\title{
Pharmacological Properties of $\gamma$-Aminobutyric Acid-, Glutamate-, and Aspartate-induced Depolarizations in Cultured Astrocytes ${ }^{1}$
}

\author{
H. KETTENMANN ${ }^{2}$ AND M. SCHACHNER
}

Department of Neurobiology, University of Heidelberg, Im Neuenheimer Feld 504, D-6900 Heidelberg, Federal Republic of Germany

\begin{abstract}
Differentiated glial fibrillary acidic protein-positive astrocytes in homogeneous cultures of early postnatal rat cerebral hemispheres respond by membrane depolarization to $\gamma$-aminobutyric acid (GABA), glutamate, and aspartate with a threshold concentration of approximately $10^{-5} \mathrm{M}$. The GABAinduced depolarization is antagonized by two blockers of the neuronal $\mathrm{GABA}_{A}$ receptor, picrotoxin and bicuculline, but is not affected by the uptake blockers $\beta$-alanine or nipecotic acid. An agonist of the GABA $A_{A}$ receptor, muscimol, produces a dose-response curve similar to that of GABA, whereas the agonist of the $\mathrm{GABA}_{B}$ receptor, baclofen, did not alter the membrane potential. When repetitive pulses of GABA are given to one cell, its responsiveness depends on the time interval between pulses. Within $30 \mathrm{sec}$ after termination of the first pulse the cell remains unresponsive to the second pulse. With increased time intervals between the pulses, reactivity toward GABA recovers. Five minutes after the first pulse the cell regains $75 \%$ of its initial depolarization peak. Aspartate results in a depolarization similar in size and time course to that induced by glutamate. The glutamate agonists, quisqualate and ibotenate, and kainate are less potent than glutamate. $\mathbf{N}$-Methyl-D-aspartate has no effect on the membrane potential of astrocytes. The pharmacological features of the glutamate response are therefore similar to those of the receptor mediating neuronal glutamate transport.
\end{abstract}

Astrocytes are the most abundant type of glial cell in the central nervous system of mammals. Their role in the regulation of the neuron's extracellular environment has been assumed to involve the clearance of $\mathrm{K}^{+}$released by electrically active neurons via spatial buffer currents (Orkand et al., 1966; Gardner-Medwin, 1983) and, as suggested by Walz et al. (1984), active uptake. Clearance of neurotransmitters released by neurons from the extracellular space is another function proposed for glia (for review, see Schousboe, 1981). In addition to this neurotransmitter uptake mechanism, cultured glial cells have been shown to respond directly by membrane depolarization to the amino acid neurotransmitters GABA, aspartate, and glutamate (Kettenmann et al., 1984a, b). Although all astrocytes from neonatal rat cerebral hemispheres showed a response to GABA, aspartate, and glutamate, but not to other neurotransmitters (Kettenmann et al., 1984b), only some oligodendrocytes from em-

Received February 19, 1985; Revised May 7, 1985;

Accepted May 23, 1985

${ }^{1}$ We thank B. Berger, M. Büttner, C. Gordillo, and M. von der Decken for technical assistance, U. Sonnhof and K. H. Backus for helpful discussions, and Hermann and Lilly Schilling-Stiftung, and DFG for support.

${ }^{2}$ To whom correspondence should be addressed. bryonic mouse spinal cord responded to GABA, others only to glutamate, and some to both, whereas yet another population remained unresponsive (Gilbert et al., 1984). Furthermore, aspartate, glycine, serotonin, adrenaline, noradrenaline, acetylcholine, and bradykinin were not observed to affect the resling mernbrane potential of these oligodendrocytes (Kettenmann et al., 1984a). More recently, a direct response of cultured astrocytes to glutamate and aspartate, but not to GABA, was reported by Bowman and Kimelberg (1984). A direct depolarizing effect of glutamate on pure glial preparations has been shown in the denervated Necturus and rat optic nerve (Tang and Orkand, 1982; Ranson and Yamate, 1984) and of bradykinin on a glioma cell line (Reiser and Hamprecht, 1982). These studies show that glial cells respond directly to neurotransmitters and not only indirectly via a neuron-mediated $\mathrm{K}^{+}$release during electrical activity (Constanti and Galvan, 1978; Hösli et al., 1981a, b).

In the mammalian central nervous system, the effects of GABA and glutamate as the most prominent inhibitory and excitatory neurotransmitters on the neuronal membrane have been the topic of many physiological and pharmacological investigations. GABA acts on two different receptive sites, the $\mathrm{GABA}_{A}$ and $G A B A_{B}$ receptors (Bowery et al., 1979; Dunlap, 1981). Receptors for glutamate can be subdivided into at least two, but probably five pharmacologically distinct classes (Foster and Fagg, 1984). Four of these receptor types are responsible for triggering conductance changes in the neuronal membrane, whereas one type is thought to mediate transmitter uptake. The ionic mechanisms involved in the glutamate- and GABA-induced depolarizations of neuronal membranes are beginning to be understood (e.g., Bührle and Sonnhof, 1984, 1985; Sakmann et al., 1984).

The scope of the present investigation was to elucidate the pharmacological features of the astrocytic responses to GABA, glutamate, and aspartate and to compare these to the properties of neurons and oligodendrocytes.

\section{Materials and Methods}

Cell culture. Cultures of enriched astrocytes were obtained from 0- to 2 day-old rat cerebral hemispheres according to the method of McCarthy and De Vellis (1980). They were approximately $98 \%$ pure as revealed by immunological criteria using glial fibrillary acidic protein as a marker for differentiated astrocytes. Cells were used for electrophysiological characterization after they had been maintained for 9 to 11 days in vitro. They were then subcultured using $10 \mu \mathrm{g} / \mathrm{ml}$ of trypsin and $1 \mathrm{~mm}$ EDTA in Hanks' balanced salt solution for 5 to $10 \mathrm{~min}$ at room temperature and were used for electrophysiological recordings 4 to 20 days after subculture.

Electrophysiological procedures. For intracellular recordings electrodes filled with $3 \mathrm{M}$ potassium acetate (resistance, 50 megohms) were used. The reference electrode consisted of an $\mathrm{Ag}$-AgCl pellet connected to the bathing fluid via a strip of filter paper. For electrophysiological recording the culture dish was mounted on the stage of a Zeiss inverted microscope and maintained at room temperature (Kettenmann et al., 1983). Cells were 
penetrated with the aid of a step motor-driven micromanipulator (Sonnhof et al., 1982). Recordings were taken from penetrations which gave stable membrane potentials over many hours. Recording, storage, and display of data were accomplished with conventional electrophysiological equipment and a microcomputer system. The bathing fluid contained the following salts in millimolar concentration: $\mathrm{NaCl}, 116 ; \mathrm{KCl}, 5.4 ; \mathrm{CaCl}_{2}, 1.8 ; \mathrm{NaHCO}_{3}, 26$; $\mathrm{NaHPO}_{4}, 1 ; \mathrm{MgSO}_{4}, 0.8$; glucose, 5.5. The $\mathrm{pH}$ of the bathing fluid was controlled by a $\mathrm{CO}_{2}$ atmosphere. The bathing fluid could be exchanged during experiments within 1 min by bath perfusion. Substances to be tested were added to the bathing fluid.

Neurotransmitters, agonists, and antagonists were obtained from Sigma (München, Federal Republic of Germany) and were used in the following concentrations: GABA, L-glutamate, L-aspartate, quisqualate, kainate, and ibotenate at $0.001 \mathrm{~mm}, 0.005 \mathrm{~mm}, 0.01 \mathrm{~mm}, 0.1 \mathrm{~mm}, 1 \mathrm{~mm}, 10 \mathrm{~mm}$ (except for ibotenate and quisqualate); nipecotic acid, $1 \mathrm{~mm} ; \beta$-alanine, $1 \mathrm{~mm}$; muscimol, $1 \mathrm{~mm}$; picrotoxin, $0.1 \mathrm{~mm}$. Bicuculline was used as methobromide at a concentration of $0.5 \mathrm{~mm}$.

\section{Results}

Dose-response curve of GABA-induced depolarization. Application of $1 \mathrm{~mm}$ GABA resulted in a transient depolarization of cultured astrocytes as previously described (Kettenmann et al., 1984b). The depolarization was followed by a repolarization within about half a minute. To test the response of the cells to different concentrations, recordings were taken from one cell to which pulses of GABA were applied at increasing concentrations $(1 \mu \mathrm{M}, 5 \mu \mathrm{M}, 10 \mu \mathrm{M}, 100 \mu \mathrm{M}, 1$ $\mathrm{mm}, 10 \mathrm{~mm}$ ) at 5- or 10-min intervals to decrease desensitization ( $N$ $=8 ;$ Fig. $1 \mathrm{~A}$ ). The lowest concentration which caused a recognizable membrane reaction was $5 \mu \mathrm{M}$. The maximal depolarization response was found at $1 \mathrm{~mm}$. At a higher concentration $(10 \mathrm{~mm})$ the depolarizing response in some cases even became smaller. The time course of the depolarization also varied with the concentration (Fig. 1A) The speed of de- and repolarization (as expressed in volts per second) was enhanced with higher concentrations. A typical doseresponse curve is displayed in Figure $1 \mathrm{C}$.

Desensitization of GABA response. The GABA response of astrocytes showed a depolarization followed by a repolarization. This repolarization phase also occurred during sustained application and therefore was not induced by replacement of the bath with GABAfree solution. The membrane potential repolarizes either to the original value or to an intermediate plateau (Kettenmann et al., 1984b). This response therefore has the features of a desensitization process (Dunlap, 1981). By applying two GABA pulses of short duration (30 sec) and varying the time interval between the pulses ( 0.5 to $7 \mathrm{~min}$ ), the recovery of the GABA response was determined (Fig. 2). When GABA pulses were given within time intervals of less than $1 \mathrm{~min}$, no second GABA response could be seen. After an
(A)

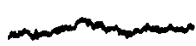

$10^{-6}$

(B)
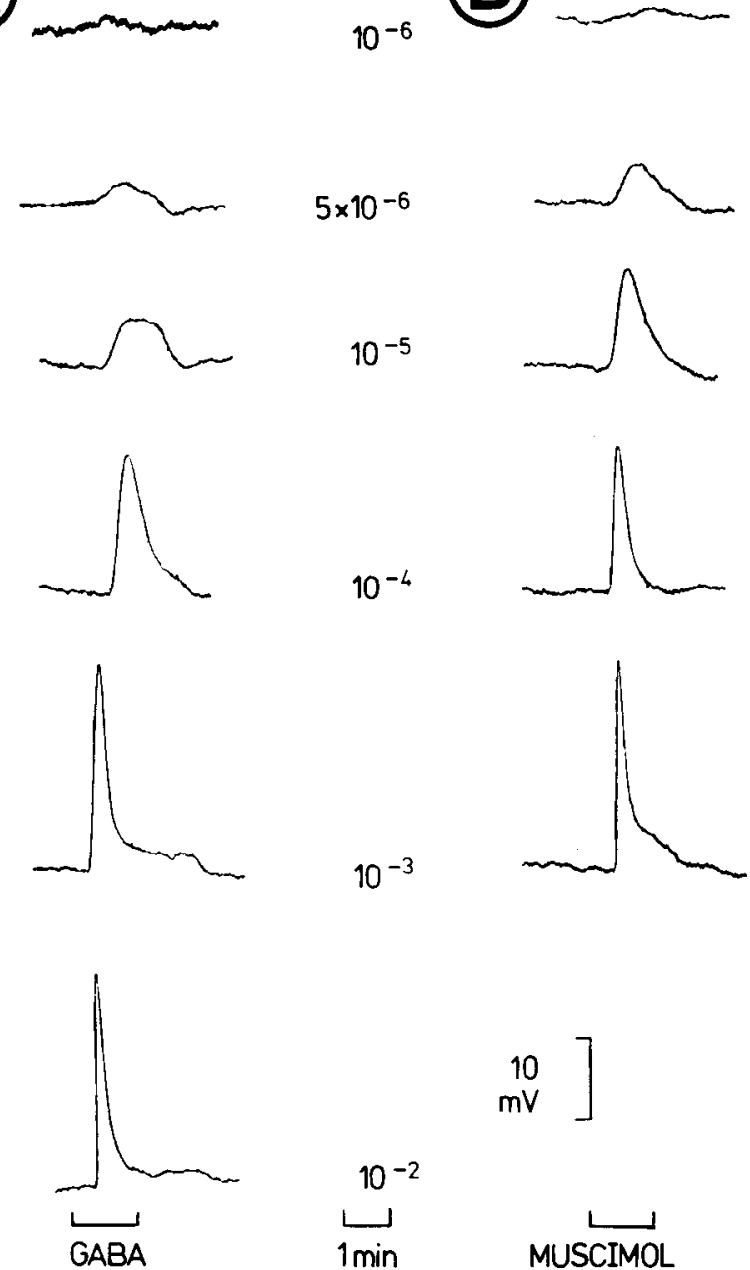

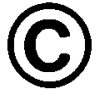

$\Delta V_{m}$
$[m V]$

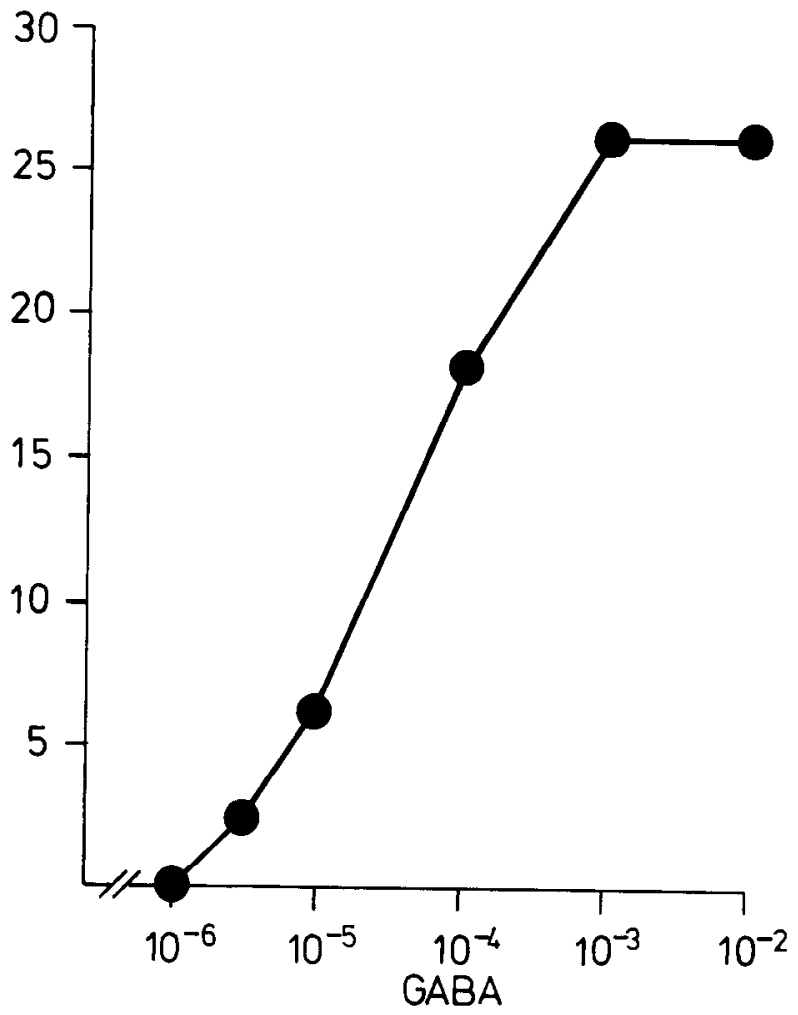

Figure 1. Effect of GABA and muscimol on the membrane potential at different concentrations. During recording of membrane potential different concentrations of GABA $(A)$ and muscimol $(B)$ were applied to an astrocyte beginning with the lowest concentration $\left(10^{-6} \mathrm{M}\right)$. Concentrations are given in molar concentrations. Resting membrane potential was $-75 \mathrm{mV}$. The substances were applied by bath perfusion as indicated by the bars. The time interval between applications was $10 \mathrm{~min}$. C, Dose-response curve of the GABA action. The change in membrane potential $\left(\Delta V_{\mathrm{m}}\right)$ was plotted against the molar concentration of the applied GABA. 


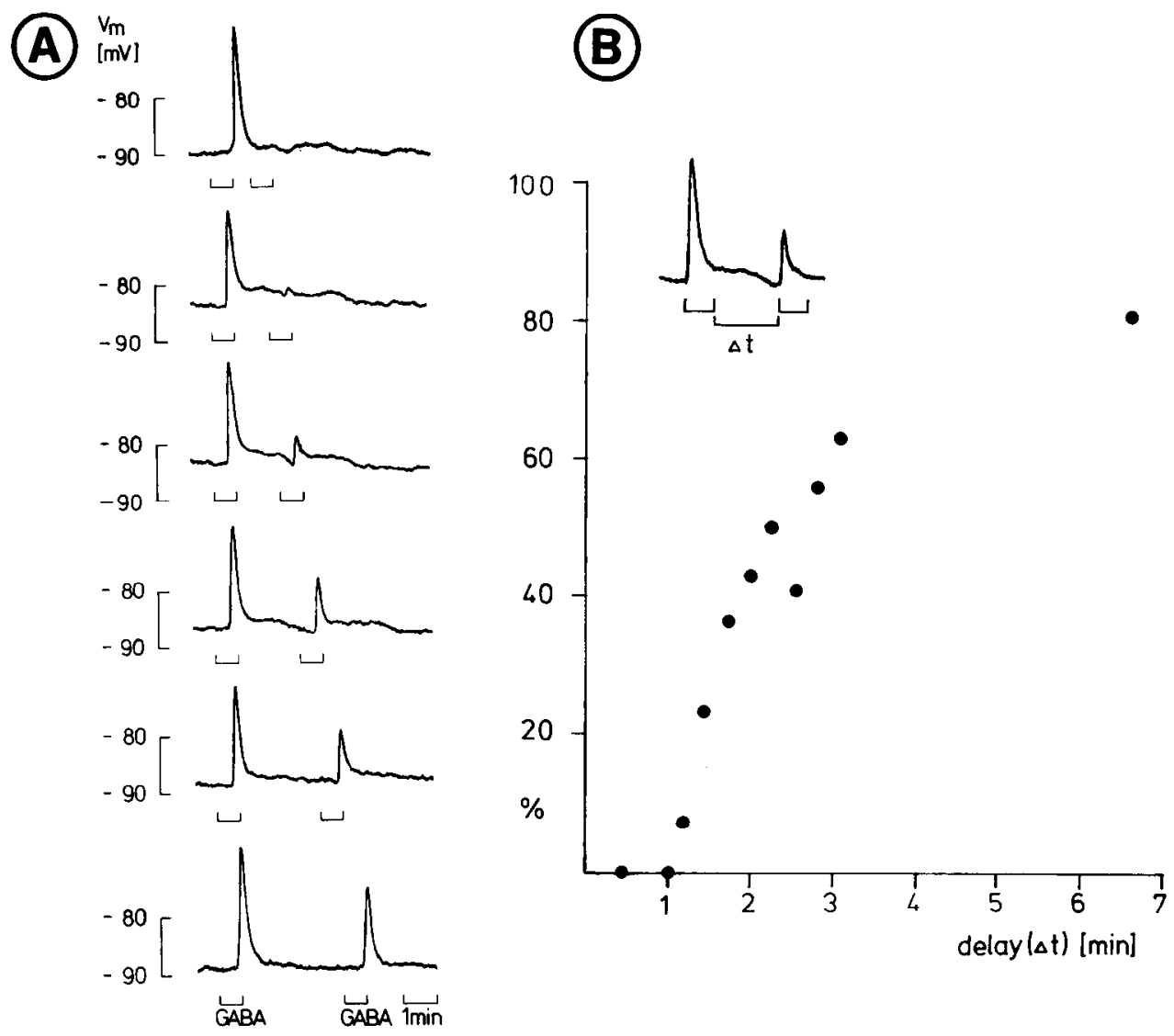

Figure 2. $A$, Desensitization of the GABA response. GABA (1 mM) was applied several times in double pulses to an astrocyte during recording of membrane potential $\left(V_{m}\right)$ as indicated by the bar. The time between the double pulses was varied between 0.5 and $3 \mathrm{~min}$. The time interval between each set of double pulses was $10 \mathrm{~min}$. $B$, Quarntitative determination of the refractory period of the GABA-induced response. The relative size (in percentage of the first response) of a second response after a GABA pulse as a function of time between the two pulses was determined as described in $A$. The inset at upper left shows the definition of $\Delta t$, the time interval (delay) between double puises.
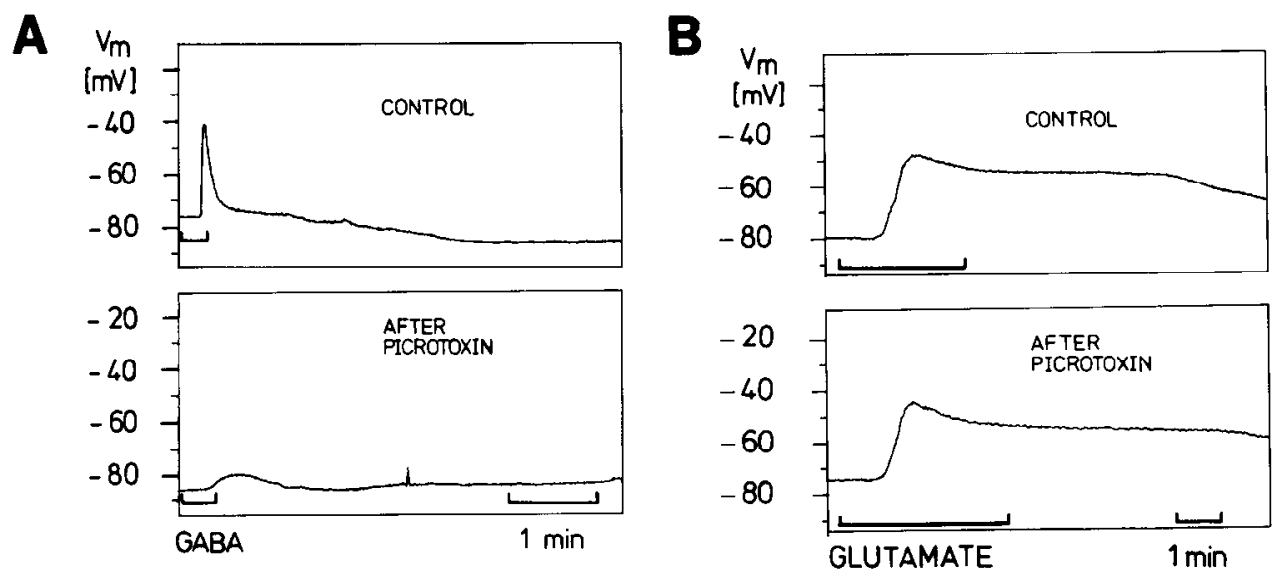

Figure 3. Effect of picrotoxin on the GABA- and glutamate-induced membrane response. The reaction of the membrane potential $\left(V_{m}\right)$ to GABA $(A)$ and glutamate $(B)$ was measured after previous application (3 min) of $0.1 \mathrm{~mm}$ picrotoxin (AFTER PICROTOXIN) and compared to a control without previous application of picrotoxin (CON$T R O L)$. The perfusion times are indicated by bars.

interval of about 1 min a very small response of the cell was seen. After about $5 \mathrm{~min}$ the second reaction was $75 \%$ of the original response (Fig. 2). In some cases the GABA response became smaller after multiple application of different drugs and after recording for more than $4 \mathrm{hr}$.

Effect of GABA agonists and antagonists. The response of astrocytes to muscimol, an agonist of the neuronal $\mathrm{GABA}_{A}$ receptor, was tested at different concentrations and compared to the response to GABA. Depolarizations were similar in size and time course to those elicited by GABA (Fig. 1). At the lower concentrations of $5 \times 10^{-6}$ to $10^{-4} \mathrm{M}$, muscimol was more effective than GABA. Similar to GABA, the muscimol response desensitized during application $\left(N=7\right.$; Fig. $1 B$ ). The agonist of the neuronal $G A B A_{B}$ receptor, baclofen, did not alter the membrane potential of astrocytes $(N=$ $5)$.
When antagonists of the $\mathrm{GABA}_{\mathrm{A}}$ receptor, picrotoxin $(0.1 \mathrm{~mm})$ and bicuculline $(0.5 \mathrm{~mm})$, were added to the bath $2 \mathrm{~min}$ before a GABA pulse, the GABA response was reduced by more than $90 \%$ ( $N=15$; Fig. $3 A$ for picrotoxin) when compared to the response to GABA before addition of antagonists. GABA responsiveness was recovered $10 \mathrm{~min}$ after washing out the antagonists.

Blockers of the GABA uptake, nipecotic acid ( $1 \mathrm{~mm})$ and $\beta$-alanine $(1 \mathrm{mM})$, did not influence the GABA-induced depolarization $(N=5$; not shown)

Dose-response curves of glutamate- and aspartate-induced depolarizations. In addition to GABA, cultured astrocytes also responded to glutamate and aspartate by depolarization (Bowman and Kimelberg, 1984; Kettenmann et al., 1984b). A rapid application of the transmitter was necessary to give reproducible responses. The normal speed of exchange was about $80 \%$ within $20 \mathrm{sec}$ 


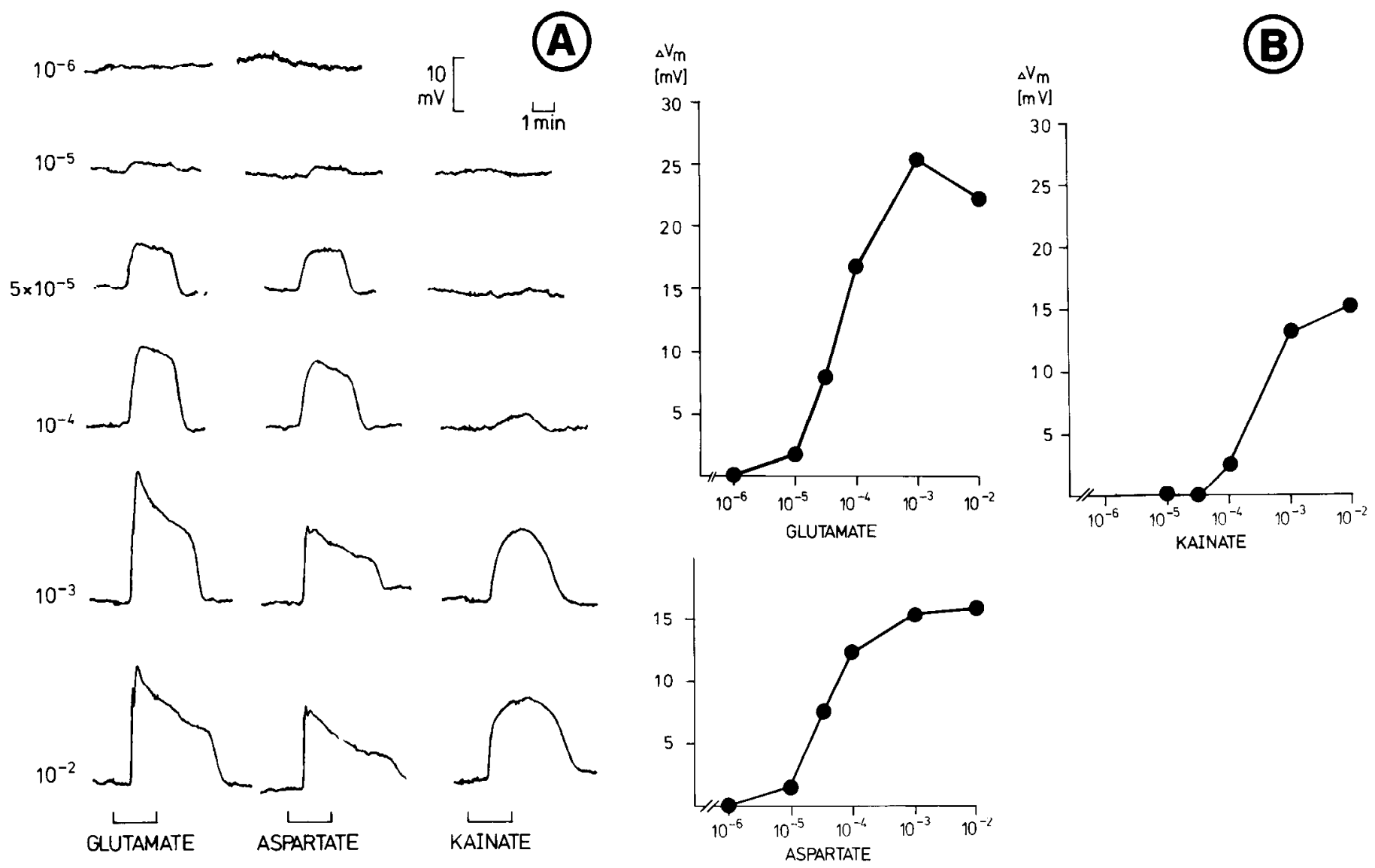

Figure 4. A, Concentration dependence of the glutamate-, aspartate-, and kainate-induced depolarization. The effect of increasing concentrations of glutamate, aspartate, and kainate (beginning with $10^{-6} \mathrm{M}$ ) on membrane potential (in millivolts) was tested on one astrocyte. The resting membrane potential of the astrocyte was $-85 \mathrm{mV}$. Concentrations are given in molar concentrations. Time of application of the drugs is indicated by bars. $B$, Dose-response curves of glutamate, aspartate, and kainate induced membrane depolarization as shown in $A$. Changes in membrane potential $\left(\Delta V_{\mathrm{m}}\right)$ were plotted against the concentration of applied glutamate, aspartate, and kainate (in millimolar concentration).

(Kettenmann et al., 1983) and was kept constant during the experiments. Reduction in the perfusion speed resulted in smaller depolarizations with a slower de- and repolarization phase.

The dose-response curve of glutamate and aspartate was determined at increasing concentrations in 10-min intervals to decrease desensitization (Fig. 4). The threshold concentration for glutamate was slightly above $1 \mu \mathrm{M}$. The plateau of the response to glutamate was reached at $1 \mathrm{~mm}$. Higher concentrations resulted in the same or even smaller depolarizations. The time course of the depolarization was concentration dependent. In addition, higher concentrations increased the speed of depolarization. Aspartate resulted in a depolarization which was similar in time course, concentration dependence, and size to the glutamate-induced response ( $N=14$; Kettenmann et al., 1984b).

Prolonged and repetitive application of glutamate. Prolonged application of glutamate resulted in repolarization to an intermediate level (Fig. 5). After replacing glutamate by normal bathing medium, the membrane potential repolarized to the value prior to glutamate application. Repetitive applications of glutamate with increasing intervals between applications are shown in Figure 6 . The second application results in a depolarization smaller than the previous one. Since the series of measurements was performed on one cell, time intervals between double pulses were $10 \mathrm{~min}$. Note that the first trial resulted in a larger depolarization than the last one. This was always the case when glutamate was applied in several trials on one cell.

Effect of glutamate agonists. The responses of astrocytes to agonists of the neuronal glutamate receptors were studied. Kainate at a concentration of $1 \mathrm{~mm}$ depolarized astrocytes similar to glutamate. The time course of the initial slope of depolarization, however,

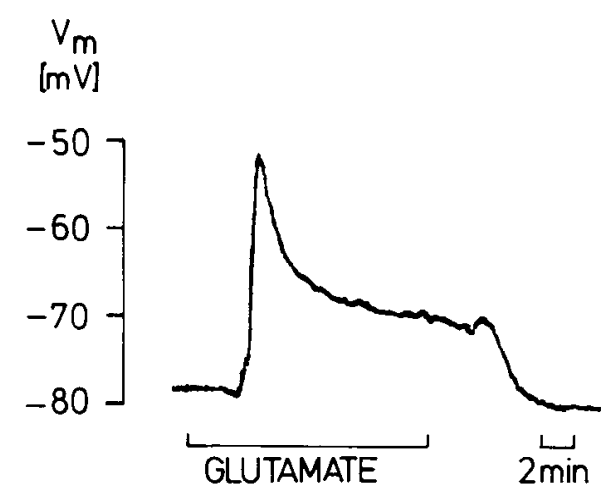

Figure 5. Effect of prolonged glutamate application on membrane depolarization. A pulse of glutamate was given for $7 \mathrm{~min}$ to an astrocyte during recording of membrane potential $\left(V_{m}\right)$.

was slower. At lower concentrations glutamate was more effective than kainate, the threshold being $50 \mu \mathrm{M}(N=18$; Fig. 4). Ibotenate $(N=3)$ and quisqualate $(N=4)$ (Fig. 7) resulted in a smaller depolarization than that induced by glutamate. $N$-Methyl-D-aspartate (1 mM) did not change the membrane potential of astrocytes $(N=$ 21) (Fig. 7).

The antagonists of the neuronal $\mathrm{GABA}_{\mathrm{A}}$ receptor, picrotoxin and bicuculline, did not alter the glutamate- and aspartate-induced depolarization (Fig $6 B$ for picrotoxin and glutamate application).

Effect of glutamate on the responsiveness to $G A B A$. In this set of experiments it was tested whether the GABA reaction could still 
be evoked during application of glutamate. The responses to GABA before and during application of glutamate were compared. As seen in Figure 8, GABA induced a depolarization during glutamate application. When the peak of the glutamate-induced depolarization was much larger than the GABA-evoked depolarization, addition of GABA during glutamate action resulted in a less than additive depolarization (Fig. 8A). When the glutamate-induced depolarization was smaller than that evoked by GABA, the values of the GABA- and glutamateinduced depolarizations were additive (Fig. $8 B$ ). We conclude that the GABA- and glutamate-induced depolarizations are induced by two distinct mechanisms which may interfere with each other.
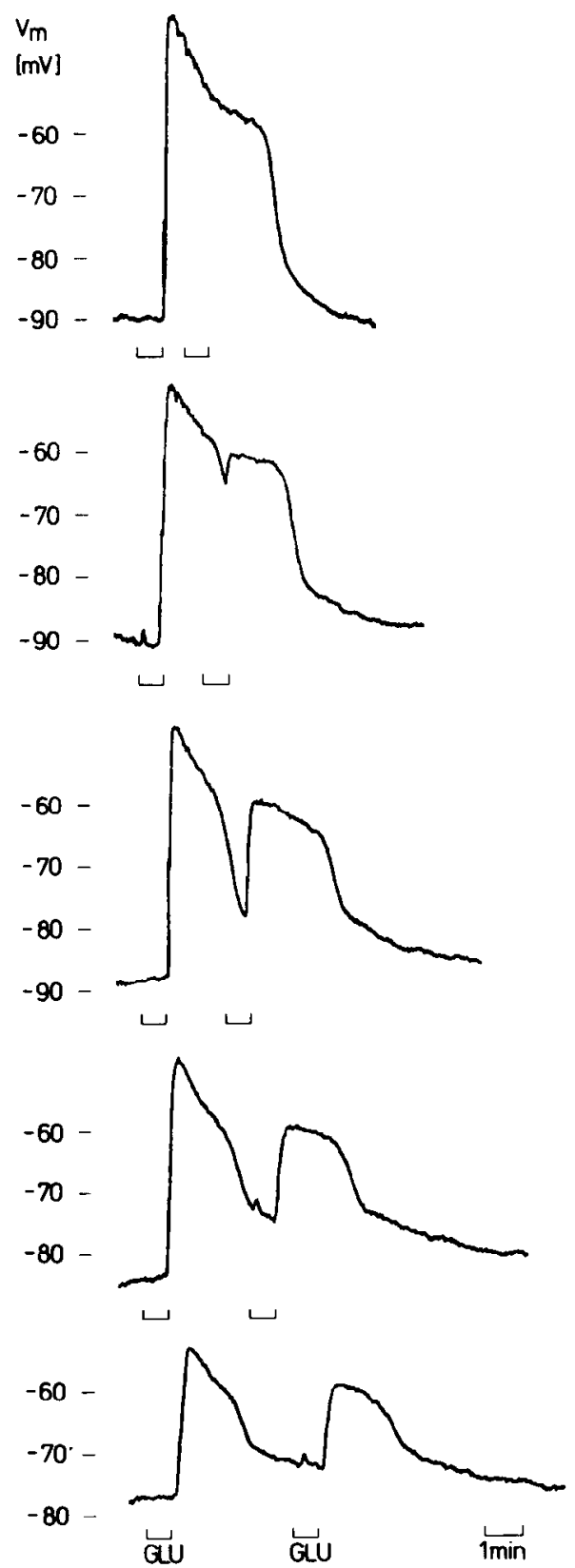

Figure 6. Desensitization of the glutamate response. Glutamate was applied twice during recording of membrane potential $\left(V_{m}\right)$ with an increasing interval between the two pulses as indicated by bars. The interval was varied between 0.5 and $3 \mathrm{~min}$. The recordings were performed on one cell with a time in between each set of double pulses of $10 \mathrm{~min}$. To decrease desensitization, time intervals between sets of double pulses were kept at a minimum of $10 \mathrm{~min}$.
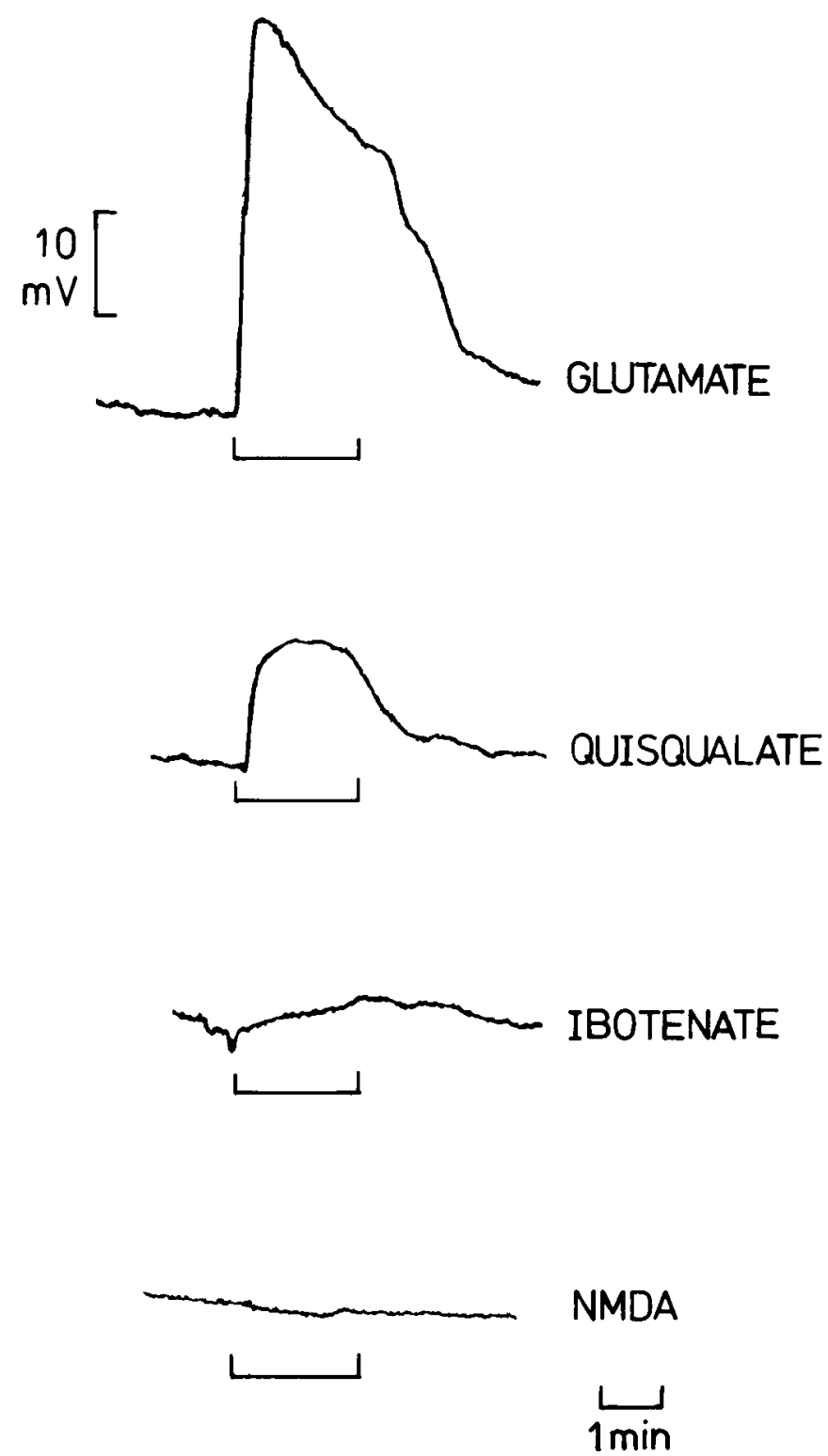

Figure 7. Effect of quisqualate, ibotenate, and N-methyl-D-aspartate (NMDA) on membrane potential. During recording of membrane potential, glutamate, quisqualate, ibotenate, and $N$-methyl-D-aspartate were applied by bath perfusion ( $1 \mathrm{~mm}$ ) as indicated by bars. Time interval between applications was $10 \mathrm{~min}$. Resting membrane potential was $-80 \mathrm{mV}$.

\section{Discussion}

The present study has confirmed and extended previous observations that cultured astrocytes are able to react directly to the neurotransmitters GABA, glutamate, and aspartate by depolarization (Kettenmann et al., 1984b). Since the cultures have a high purity with respect to cell type (>98\%; Keilhauer et al., 1985), an influence of other cells could be excluded (see also Kettenmann et al., 1984b). Bowman and Kimelberg (1984) also described glutamate- and aspartate-induced depolarizations in cultured astrocytes. In the concentration range of glutamate and aspartate from $10^{-6}$ to $10^{-3} \mathrm{M}$, we obtained similar results, whereas with higher concentrations of glutamate $(10 \mathrm{~mm})$ we found a decrease in the size of the response. However, their results are based on measurements from only two cells. Also, in contrast to our observations, these authors did not detect GABA-induced depolarizations in their astrocyte cultures. It is noteworthy in this respect that, after repetitive application of different 
A

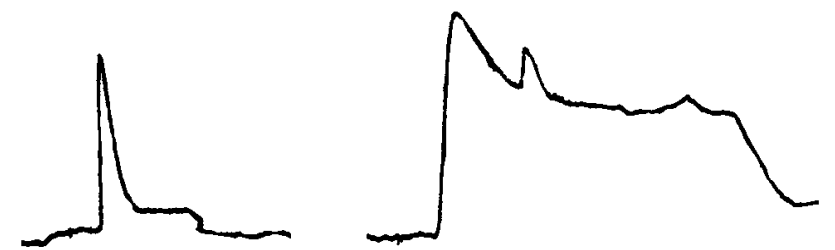

B

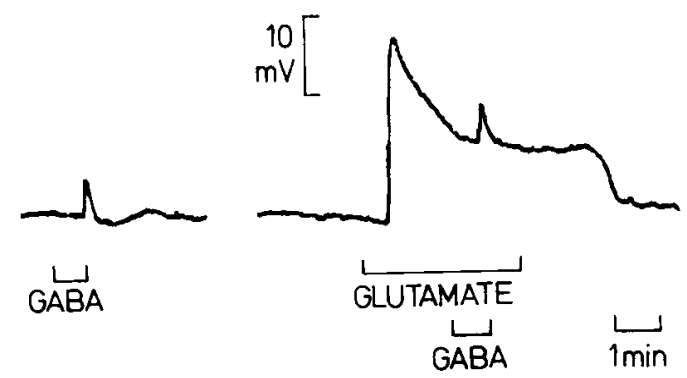

Figure 8. Effect of GABA on membrane potential in the absence of and during a glutamate pulse. Concentrations of GABA and glutamate were in all cases $10^{-3} \mathrm{M}$. Application times are indicated by bars. Resting membrane potential was $-75 \mathrm{mV}$. A, Application of GABA during a glutamate pulse led to a depolarizing level similar to that induced by GABA alone. $B_{i}$ in another cell, GABA induced a smaller depolarization when applied alone, whereas application of GABA during the glutamate pulse resulted in a superimposed depolarization of similar size.

drugs to one astrocyte, the GABA response was found to be decreased. If GABA had been tested at the end of a series of experiments in our cultures, a response of the cell could have been overlooked. It is also possible that the developmental stage of the astrocyles under investigation and their origin with regard to brain region plays an important role.

Comparison of GABA- and glutamate-induced depolarization in oligodendrocytes. GABA and glutamate depolarize cultured oligodendrocytes from embryonic mouse spinal cord (Gilbert et al., 1984; Kettenmann et al., 1984a). For a given concentration the size of the depolarization is significantly smaller in oligodendrocytes than in astrocytes, both for glutamate and GABA. The time course of the depolarization curves is similar to that observed in cultured astrocytes from rat cortex (Bowman and Kimelberg, 1984; Kettenmann et al., 1984b), and the GABA response in oligodendrocytes and astrocytes can be mimicked by muscimol and antagonized by bicuculline and picrotoxin. The pharmacological properties of the glutamate response have not been studied in oligodendrocytes. In contrast to astrocytes, however, only a percentage of all oligodendrocytes tested responded to GABA and glutamate. We therefore conclude that, despite many similarities in electrophysiological and pharmacological features of astrocytes and oligodendrocytes, some differences in membrane properties in response to neurotransmitters are evident. Whether these are due to different culture conditions or to developmental, brain region-specific, or functional differences remains to be elucidated.

Pharmacological properties of the GABA response with relation to the neuronal GABA receptor. In neurons, two different GABAreceptive sites can be pharmacologically distinguished (Dunlap, 1981). The pharmacological properties of the astrocytic GABA response are similar to those of the $\mathrm{GABA}_{\mathrm{A}}$ receptor site of neurons, regarding the depolarizing effect of muscimol and the antagonizing effect of bicuculline and picrotoxin. They do not match with the pharmacological properties postulated for the $\mathrm{GABA}_{\mathrm{B}}$ receptor site or with a GABA uptake process (Schousboe, 1981). The ionic mechanisms underlying the membrane depolarizaton of glial cells to GABA are presently unknown.

Pharmacological properties of the glutamate and aspartate response with relation to the neuronal glutamate receptor. The pharmacological properties of the neuronal transport binding site for glutamate and aspartate (Foster and Fagg, 1984) show the best agreement with the reactions of astrocytes reported here: the depolarizing response in astrocytes is induced by glutamate and aspartate and the cells are less sensitive to ibotenate, quisqualate, and kainate (at lower conentrations). N-Methyl-D-aspartate shows no effect. The transport binding site is also dependent on extracellular $\mathrm{Na}^{+}$as shown for the astrocytic glutamate-induced depolarization (Bowman and Kimelberg, 1984). The depolarizing response of oligodendrocytes and astrocytes to glutamate could therefore reflect a glial counterpart of the neuronal uptake mechanism.

Possible function and mechanism of transmitter-induced depolarization in glial cells. The functional role of GABA and glutamate in participating in the information transfer between neurons is well established. The action of the neurotransmitters is mediated by a change of ionic conductances of the neuronal membrane causing de- or hyperpolarization of the cell. Similar to the GABA response of oligodendrocytes (Gilbert et al., 1984), the observed depolarization of astrocytes, however, may not be due to conductance changes. A possibility for the depolarization mechanism is the activation of a pump or a carrier system. For glial cells $\mathrm{Na}^{+}$-dependent transmitter transport mechanisms have been described (Schousboe, 1981). The movement of $\mathrm{Na}^{+}$into the cell could thus lead to the observed depolarization (Krnjevic, 1984). The GABA-induced depolarization in oligodendrocytes (Gilbert et al., 1984) and the glutamate-induced depolarization of astrocytes is dependent on extracellular $\mathrm{Na}^{+}$(Tang and Orkand 1982; Bowman and Kimelberg, 1984). Shank and Campbell (1984) found that a cell fraction containing astrocytes from the mouse cerebellum possess higher affinity carriers for glutamate and GABA in comparison to other fractions. We therefore favor the hypothesis that the transmitter-induced depolarization in astrocytes and oligodendrocytes is due to an uptake process driven by the $\mathrm{Na}^{+}$gradient across the membrane. The uptake of GABA would be different from that of the nipecotic acid-sensitive system. However, no convincing experimental evidence is yet provided to link the observed membrane reaction with a functional role.

\section{References}

Bowery, N. G., A. Doble, D. R. Hill, A. L. Hudson, J. S. Shaw, and M. J. Turnbull (1979) Baclofen: A selective agonist for a novel type of GABA receptor. Br. J. Pharmacol. 67: 444P-445P.

Bowman, C. L., and H. K. Kimelberg (1984) Excitatory amino acids directly depolarize rat brain astrocytes in primary culture. Nature 311: 656-659.

Bührle, C. P., and U. Sonnhof (1984) The ionic mechanism of the excitatory action of glutamate upon the membranes of motoneurones of the frog. Pflügers Arch. 396: 154-162

Bührle, C. P., and U. Sonnhof (1985) The ionic mechanism of postsynaptic inhibition in motoneurones of the frog spinal cord. Neuroscience 14: 581-592.

Constanti, A., and M. Galvan (1978) Amino acid-evoked depolarization of electrically inexcitable (neuroglial?) cells in the guinea pig olfactory cortex slice. Brain Res. 153: 183-187.

Dunlap, K. (1981) Two types of $\gamma$-aminobutyric acid receptors on embryonic sensory neurones. Br. J. Pharmacol. 74: 579-585

Foster, A. C., and G. E. Fagg (1984) Acidic amino acid binding sites in mammalian neuronal membranes: Their characteristics and relationship to synaptic receptors. Rrain Res. Rev. 7: 103-164.

Gardner-Medwin, A. R. (1983) A study of the mechanisms by which potassium moves through the brain tissue in the rat. J. Physiol. 335: 353-374.

Gilbert, P., H. Kettenmann, and M. Schachner (1984) $\gamma$-Aminobutyric acid directly depolarizes cultured oligodendrocytes. J. Neurosci. 4: 561-569.

Hösli, L., E. Hösli, H. Landolt, and C. Zehntner (1981a) Efflux of potassium Irom neurones excited by glutamate and aspartate causes a depolarization of cultured glial cells. Neurosci. Lett. 21: 83-86,

Hösli, L., E. Hösli, P. F. Andres, and H. Landolt (1981b) Evidence that the depolarization of glial cells by inhibitory amino acids is caused by an efflux of $\mathrm{K}^{+}$from neurones. Exp. Brain Res. 42: 43-48.

Keilhauer, G., D. H. Meier, S. Kuhlmann, J. Nieke, and M. Schachner (1985) Astrocytes support incomplete differentiation of an oligodendrocyte precursor cell. EMBO J., in press.

Kettenmann, H., U. Sonnhof, and M. Schachner (1983) Exclusive potassium 
dependence of the membrane potential in cultured mouse oligodendrocytes. J. Neurosci. 3: 500-505.

Kettenmann, H., P. Gilbert, and M. Schachner (1984a) Depolarization of cultured oligodendrocytes by glutamate and GABA. Neurosci. Lett. 47 : 271-276.

Kettenmann, H., K. H. Backus, and M. Schachner (1984b) Aspartate, glutamate and $\gamma$-aminobutyric acid depolarize cultured astrocytes. Neurosci. Lett. 52: $25-29$

Krnjevic, K. (1984) Some functional consequences of $\mathrm{Na}^{+}$-linked GABA uptake, Neurosci. Lett. 47: 283-287.

McCarthy, K. D., and J. De Vellis (1980) Preparation of separate astroglial and oligodendroglial cell cultures from rat cerebral tissue. J. Cell Biol. 85: 890-902.

Orkand, R. K., J. G. Nicholls, and S. W. Kuffler (1966) The effect of nerve impulses on the membrane potential of glial cells in the central nervous system of amphibia. J. Neurophysiol. 29: 788-806.

Ransom, B. R., and C. L. Yamate (1984) The rat optic nerve following enucleation: A pure preparation of mammalian glia. Soc. Neurosci. Abstr. 10: 949 .

Reiser, G., and B. Hamprecht (1982) Bradykinin induces hyperpolarization in rat glioma cells and in neuroblastoma $\times$ glioma hybrid cells. Brain Res. 239: 191-199.

Sakmann, B., O. P. Hamill, and J. Bormann (1984) Patch-clamp measurements of elementary chloride currents activated by the putative transmitter GABA and glycine in mammalian spinal neurons. J. Neural Transmission Suppl. 18: 83-95.

Schousboe, A. (1981) Transport and metabolism of glutamate and GABA in neurons and glial cells, Int. Rev. Neurobiol. 22: 1-45.

Shank, R. P., and G. L. Campbell (1984) Amino acid uptake, content and metabolism by neuronal and glial enriched cellular fractions from mouse cerebellum. J. Neurosci. 4: 58-69.

Sonnhof, U., R. Förderer, W. Schneider, and H. Kettenmann (1982) Cell puncturing with a step motor driven manipulator with simultaneous control of displacement. Pflügers Arch. 392: 295-300.

Tang, C.M., and R. K. Orkand (1982) Glutamate directly depolarizes glial cells. Neuroscience 7: S 208.

Walz, W., W. Wuttke, and L. Hertz (1984) Astrocytes in primary cultures: Mernorane potential characterisics reveal exclusive potassium conduct ance and potassium accumulator properties. Brain Res. 292: 367-374. 